\title{
Lázaro Cárdenas, impulsor del turismo y el arte en Pátzcuaro.
}

\author{
José Manuel Martínez Aguilar* \\ Universidad Michoacana de San Nicolás de Hidalgo (México)
}

\begin{abstract}
Resumen: En este trabajo hacemos una revisión de las gestiones llevadas a cabo por el general Lázaro Cárdenas del Rio en favor del municipio de Pátzcuaro, para que éste aprovechara su potencial turístico en beneficio de sus habitantes. Destacamos cómo fue que el presidente de la República, quien tuvo un especial apego por esta ciudad, además de fortalecer el marco legal para la conservación de su aspecto típico y bellezas naturales, promovió obras de remodelación y mejoramiento de espacios urbanos, ordenó la construcción de monumentos artísticos y la decoración de varios edificios con pintura mural, como un reflejo de la ideología nacionalista de la posrevolución.
\end{abstract}

Palabras Clave: Historia del turismo; Arquitectura; Muralismo; Arte nacionalista.

\section{Lázaro Cárdenas, promoter of tourism and art in Pátzcuaro.}

Abstract: In this paper we review the actions taken by General Lázaro Cárdenas del Rio in favor of the municipality of Pátzcuaro, so that it can take advantage of its tourist potential for the benefit of its inhabitants. We emphasize how the President of the Republic, who had a special affection for this city, in addition to strengthening the legal framework for the conservation of its typical appearance and natural beauty, promoted works of remodeling and improvement of urban spaces, ordered the construction of artistic monuments and the decoration of several buildings with mural painting, as a reflection of the nationalist ideology of the post-revolution.

Keywords: History of tourism; Architecture; Muralism; Nationalist art.

\section{Introducción}

Desde que comenzó a funcionar el tramo ferroviario entre Morelia a Pátzcuaro en 1886, las autoridades y empresarios locales, aprovechando las bellezas arquitectónicas y naturales que poseía Pátzcuaro y sus alrededores, apostaron por invertir en obras materiales, ofertar una diversidad de medios de transporte, más y mejores hoteles, a la vez que promocionaban en los periódicos de circulación estatal y nacional excursiones a la ciudad lacustre. La apuesta por hacer de Pátzcuaro un lugar turístico que trajera beneficios económicos para los inversionistas y el resto de la sociedad estaba dando buenos dividendos, hasta el inicio de la Revolución Mexicana. (Martínez, 2017).

A partir de 1910, la inestabilidad político militar del país perturbó también la vida social y económica de la región lacustre de Pátzcuaro. La ocupación de distintos grupos armados no garantizaba la seguridad de la población local ni la de los viajeros, por lo que la actividad turística se vio truncada casi en su totalidad. En ciertas ocasiones, como lo atestiguó un periodista, se instalaban puestos militares en las afueras de la ciudad y se resguardaba el ferrocarril para cuidar a los viajeros que acudían a la popular fiesta religiosa en honor a la Virgen de la Salud, el 8 de diciembre de cada año, pero aun así la afluencia de visitantes a la ciudad era reducida en comparación con años anteriores (El Centinela, diciembre 15, 1913: 2).

Les tocaría a los gobiernos posteriores a la lucha armada la tarea de reconstruir el país en todos sentidos, aprovechando las bellezas naturales y el aspecto "típico" del municipio de Pátzcuaro para convertirlo en un

Universidad Michoacana de San Nicolás de Hidalgo, México; E-mail: majmanue1999@hotmail.com. 
destino turístico. En este sentido, Lázaro Cárdenas del Rio fue uno de los gobernantes que pudo visualizar con mayor claridad este potencial y supo canalizar recursos económicos y humanos para realizar obras de importancia que permitieran a sus habitantes aprovechar los beneficios que esta actividad podía dejarles.

Gracias al apoyo que dio Cárdenas a los respectivos presidentes municipales y a su propia iniciativa, durante su periodo como gobernador del estado de Michoacán (1928-1932) y como presidente de la República (1934-1940), los habitantes de Pátzcuaro pudieron retomar la actividad turística hasta convertir al municipio de Pátzcuaro en uno de los más atractivos para el turismo nacional e internacional. Entre otras acciones, llevó a cabo numerosas obras de embellecimiento, utilizando la arquitectura, la pintura mural y la escultura como medios para fortalecer la identidad nacional, lo que no solo atraía el interés de los extranjeros, sino que permitía la inclusión de los indígenas a la vida nacional y reivindicaba su papel en la historia de Michoacán (Jolly, 2017: 84).

En este trabajo se hace una revisión de las acciones y obras llevadas a cabo en Pátzcuaro durante las tres décadas posteriores a la Revolución Mexicana, por iniciativa del Ayuntamiento local, las organizaciones sociales y por mandato directo de Lázaro Cárdenas, con la idea de impulsar al municipio y, en particular a la ciudad, como destino turístico. Nos apoyamos en la revisión de artículos periodísticos de este periodo, bibliografía, documentos de archivo y en análisis de los vestigios materiales e intangibles de la obra que encabezó el mandatario michoacano y la sociedad local.

La revisión de periódicos locales y nacionales fue fundamental para encontrar noticias de las actividades de Cárdenas en el estado de Michoacán y en Pátzcuaro relacionadas el tema de interés. Las actas de cabildo del Archivo Municipal de Pátzcuaro también fueron de gran utilidad, ya que dan cuenta de las actividades realizadas por iniciativa de Lázaro Cárdenas. Estudios publicados, como los de Eugenio Mercado (2015, 2016 y 2018) Jennifer Jolly (2017), Eder García (2003, 2015 y 2017), así como Catherine Ettinger y Eder García (2012), quienes han abordado temas relacionados al turismo en Michoacán, principalmente del periodo postrevolucionario, ayudaron también a tener un panorama más claro sobre el tema de nuestro interés. Por último, la observación de los vestigios materiales y la memoria colectiva de la obra de Cárdenas permite entender la trascendencia de los hechos en la ciudad lacustre, y nos da elementos para confrontarlos con los documentos y noticias de la época.

\section{El turismo y el arte de la postrevolución en México}

Después de la Revolución Mexicana, el Estado mexicano y organismos privados hicieron grandes esfuerzos para fomentar el turismo en el país como una actividad generadora de riqueza y progreso, al contar con un gran potencial de sitios con belleza natural, entre los cuales destacaba Acapulco; o con historia y arquitectura, como las ruinas aztecas, Teotihuacán, Cuernavaca, Tehuacán, Chapala, Taxco y Pátzcuaro, entre otros (Mercado, 2018: 676). En Europa el turismo norteamericano había dejado una derrama importante antes de la primera guerra mundial y en México se había logrado captar la atención del turismo extranjero con resultados satisfactorios antes de la Revolución Mexicana, por lo que se tenían altas expectativas en esta industria.

A partir de 1925 se inició un programa público para construir una red nacional de carreteras; en 1926 se reconoció y se reglamentó la categoría de turista en la Ley General de Población y se creó un departamento de turismo en el Banco de México para atraer a posibles inversionistas; en 1929 se creó la Comisión Mixta Pro -Turismo que buscaba facilitar el acceso y el desplazamiento de los visitantes por el país. En el sector privado se fundó la Asociación de Propietarios y Administradores de Hoteles en 1922, se creó la Asociación Mexicana de Restaurantes Asociación Civil en 1928, la Asociación Mexicana Automovilística en 1932, así como el Touring y Automóvil Club de México (Mercado, 2018: 676-677).

Desde que tomó el cargo de presidente de México en 1934, Cárdenas impulsó el turismo, por considerarla una actividad que podía ser fuente de riqueza y que siendo explotada con responsabilidad necesariamente tendría que resultar benéfica para la sociedad. Teniendo esta premisa, en 1934 reorganizó la Secretaría de Turismo y creó una Comisión Nacional encargada del fomento y desarrollo de esta industria y una serie de subcomités regionales que serían los encargados de impulsar y orientarla debidamente. En este tenor, el gobernador de Michoacán Gildardo Magaña, en acuerdo con las políticas de Cárdenas, anunció a principios de 1938 que intensificaría el turismo en el estado, considerándolo como uno de los estados del país que despertaba mayor atracción para quienes gustaban de viajar, debido a su "maravilloso" clima, lo "pintoresco" de sus pueblos, sus costumbres, sus edificios históricos y otras atracciones (Surco, febrero 2, 1938: 2, 4). Entre las localidades más favorecidas fueron Morelia, Pátzcuaro, Uruapan y Zamora. 
Si bien es cierto que después de la expropiación petrolera los empresarios norteamericanos hicieron una campaña antimexicana, para 1939 llegaron a México del país vecino 170,000 turistas, dejando una derrama de 26,500,000 dólares, por lo que los esfuerzos del gobierno federal estaban teniendo resultados satisfactorios. Se esperaba que la afluencia de turistas aumentara luego de que el presidente de los Estados Unidos Franklin D. Roosevelt declarara una política del buen vecino, mediante la cual invitaba a sus conciudadanos a visitar México; sin embargo, el inicio de la Segunda Guerra Mundial echó abajo la predicción (Heraldo Michoacano, 18 octubre, 1940: 4).

Durante el periodo de estudio, el turismo como proyecto económico estuvo ligado al ideal de progreso, teniendo como referencia los países más desarrollados, pero destacando los valores locales, es decir, se intentaba construir o fortalecer una identidad propia, de lo "mexicano", diferenciado de lo extranjero. Se debe recordar que en los años que precedieron la Revolución Mexicana el nacionalismo como ideal social se vio reflejado en las políticas de gobierno y en manifestaciones culturales y artísticas, como la literatura, la pintura mural, la escultura y la arquitectura. El arte, pues, se convirtió en una forma de comunicar la identidad mexicana ante el visitante extranjero y el orgullo del pasado histórico. Era una hibridación entre lo moderno y lo tradicional; lo moderno entendido no tanto como corriente estilística sino como un anhelo de progreso e integración a los cambios que requería el país en su reconstrucción socio cultural y económica. En este periodo de reconstrucción, la búsqueda de identidades regionales o locales dio lugar a la recuperación de elementos que las caracterizaban. Tal era el caso de la región lacustre, donde lo "pintoresco", tuvo una valoración especial desde afuera, por lo que se convirtió también en un producto turístico (Eder, 2015).

En el caso particular de Pátzcuaro, durante el periodo postrevolucionario como nunca su imagen urbana y su arquitectura fueron retocadas con esculturas y pintura mural que representaba gobernantes prehispánicos, héroes de la independencia nacional y alegorías de la Revolución Mexicana, además de escenas de indígenas y paisajes naturales de la región, reafirmando los valores sociales y culturales, como una búsqueda de reconocimiento por parte los vecinos, los visitantes nacionales y extranjeros.

\section{Mejoras materiales en el periodo cardenista}

Al terminar la Revolución Mexicana, Pátzcuaro, como la mayoría de los poblados del país, comenzó a experimentar una lenta reconstrucción social y material. Algunas de las obras se enfocaron en reparar o construir los caminos y puentes de la ciudad, preferentemente las vías que llevaban a la estación del tren y a la salida hacía Morelia y Santa Clara del Cobre, con el fin de mejorar el intercambio comercial entre las ciudades y los pueblos; desde luego, sin dejar a un lado el transporte por tren. En 1924, por ejemplo, un grupo de empresarios avecindados en Pátzcuaro abrieron una carretera que iniciaba en el centro de la ciudad, entre la calle Ahumada y Degollado -actual Lloreda- hacia la estación del ferrocarril, para facilitar la comunicación entre el centro de población y dicha estación. ${ }^{1}$ También se renovó el ramal que pasaba por Tzintzuntzan, Quiroga y llegaba hasta Morelia (Barriga y Mendoza, 2010: 74-76), lo que facilitó el desplazamiento de peregrinos y turistas de la capital hacia Pátzcuaro, que se extendió más a partir de 1938, cuando la apertura de la carretera México-Morelia-Guadalajara permitió mejorar la comunicación por automóvil o camiones de pasajeros a las dos ciudades más grandes del país con Morelia, otra ciudad que también se posicionaba como un destino turístico (Heraldo Michoacano, octubre 30, 1938: 4). En este año también se mejoró el tramo carretero entre Pátzcuaro y Ario de Rosales, lo que favoreció la actividad mercantil entre ambos poblados y localidades cercanas.

En la década de 1930, con el respaldo del gobierno estatal, los presidentes municipales en turno, entre los que destaca José Ramos Chávez, llevaron a cabo mejoras materiales en la ciudad, como arreglos en la plazuela de la Basílica y en la de San Agustín, empedrado de calles, embanquetado y empedrado de los frentes de los templos, la construcción de un puente en la colonia La Ascensión, así como la colocación de luminarias en el camino de la estación del ferrocarril y en el centro de la ciudad. En 1923 y 1935 se realizaron también obras para entubar el agua potable y actualizar el alcantarillado de la ciudad, mejorando las que se habían llevado a cabo en 1901 (La Libertad, junio 7, 1901: 2). En 1935 se le encargó al ingeniero militar Antonio Rojas García la construcción de un nuevo muelle cerca de la isla de San Pedrito, para facilitar a los turistas transportarse hacia diferentes pueblos de la ribera del lago o a las islas, ya que antes de esta fecha el muelle general era el único punto de salida para quienes deseaban navegar de Pátzcuaro a Janitzio, Tzintzuntzan y los pueblos ribereños (Fernández, 1936: 36).

Mientras Lázaro Cárdenas fue gobernador de Michoacán, presidente de la República y después de ser mandatario, estuvo interesado en abonar significativamente para que se llevaran a cabo más obras que beneficiaran a la sociedad. Muchas de ellas de infraestructura, equipamiento urbano y embellecimiento 
de plazas y espacios urbanos. Varias acciones fueron gestionadas y efectuadas por el municipio, pero otras abiertamente se anunciaron como iniciativas de Lázaro Cárdenas. Un ejemplo de esto último fue la construcción de una nueva planta hidroeléctrica, a partir de 1937, que se dijo fue impulsada por Cárdenas. El agua de manantial que hacía trabajar la planta era más pura que la que se consumía en la ciudad, por lo que el presidente Lázaro Cárdenas, "demostrando una vez el cariño que profesa a Pátzcuaro", decía una nota de periódico, contrató al propietario de la empresa de luz y fuerza, Luis Ortiz, para que entubara el agua hacia la ciudad lacustre y tuviera la mayor pureza para el consumo de los habitantes (Heraldo Michoacano, noviembre 1, 1938: 13). En marzo de 1941 el mandatario federal hizo una visita a San Gregorio para verificar que se hicieran reparaciones en la tubería que llevaba el agua de manantial de este lugar hacia Pátzcuaro (AHMP, actas de cabildo, 1941: 124).

Otra de las obras claramente impulsada por Cárdenas fue la construcción del primer mercado municipal de Pátzcuaro. No buscaba sustituir al tradicional tianguis semanal que se realizaba en la plaza principal y en la plazuela de San Agustín, sino que se esperaba tener un lugar donde se pudiera comprar y vender productos de la región todos los días de la semana, al mismo tiempo que se reubicaban un gran número de estanquillos, conocidos como "cajones comerciales", que circundaban los principales espacios públicos de la ciudad, que afectaban la imagen de las plazas. Fue así que el 21 de septiembre de 1935 Cárdenas mandó expropiar y demoler las casas de la manzana novena del cuartel primero, a un costado del ex convento de San Agustín para que se construyera el mercado municipal, mismo que fue inaugurado el 20 de marzo de 1937, con un costo de 90026.59 pesos (Vida, julio 23, 1951: 1).

\section{El arte nacionalista y el turismo en el proyecto de Cárdenas}

Durante el gobierno de Lázaro Cárdenas, el fomento a la educación y la cultura fue impulsada ampliamente. Es muy conocido el hecho de que en 1950 el entonces expresidente donó un predio donde se ubicaba su quinta Eréndira para que se creara un Centro Regional para la Formación de Personal y la Preparación de Material de Educación de Base en América Latina, que después se conoció como CREFAL. Sin embargo, uno de los primeros proyectos culturales que promovió Cárdenas fue la instauración, entre 1932 y 1936, del Museo Etnográfico, actual Museo de Artes Populares, en el primitivo Colegio de San Nicolás de Pátzcuaro.

Otro de los edificios destinados para la cultura, impulsado por Cárdenas, fue la construcción de un teatro público. El último inmueble con este uso, llamado Salón Apolo, había sido desmontado en 1932 por lo que la ciudad requería uno nuevo. Fue hasta 1936 que Cárdenas solicitó al Departamento de Monumentos Coloniales que comisionara al arquitecto Albert Le Duc y al ingeniero H. Gómez para que construyeran un edificio que serviría como teatro, demoliendo lo que quedaba del ex convento de San Agustín, edificio del siglo XVIII (AHMP, actas de cabildo, 1936: 40). El nuevo teatro se inauguró el domingo 3 de octubre de 1937 y se le puso como nombre Emperador Caltzontzin, en honor al último rey tarasco (Surco, octubre 3, 1937: 3). Como en otras obras ordenadas por el general Cárdenas, la idea de rendir tributo a los héroes nacionales y especialmente a los antiguos gobernantes tarascos se hacía presente en el nombre de este inmueble.

El diseño tomó como inspiración algunos elementos constructivos del ex convento demolido, como los marcos barrocos de puertas y ventanas; además reutilizó los arcos de cantería del claustro para la fachada principal, dando por resultado un edificio híbrido entre neocolonial y art decó. La altura del teatro fue superior a la que tenía el ex convento y a las edificaciones colindantes, exceptuando el templo, por lo que no logró integrarse del todo al contexto urbano, si es que esa era la intención del diseñador. Lo que sí preocupaba era que la construcción había puesto en riesgo de desplome el antiguo templo de San Agustín colindante, por lo que se tuvieron que tomar las previsiones correspondientes para solventar el problema (AHMP, actas de cabildo, 1936: 52).

El 16 de marzo de 1936 el templo de San Agustín fue secularizado y quedó en resguardo federal. El 23 de octubre del mismo año, mediante decreto, se estableció que el edificio fuese acondicionado como la primera biblioteca pública municipal y que llevase el nombre de la heroína de la independencia doña Gertrudis Bocanegra. El 11 de marzo de 1940, también por medio de un decreto presidencial, el edificio fue declarado monumento nacional, por los valores arquitectónicos e históricos que representaba. En este recinto, el presidente Lázaro Cárdenas inauguró personalmente, el 14 de abril de 1940, el Primer Congreso Indigenista Interamericano, al que acudieron delegaciones de todos los países de América (Barriga y Mendoza, 2010: 171). Menos de un año después, en febrero de 1941, el arquitecto y artista plástico Juan O'Gorman, pintó en su interior un fresco que narra la historia de Michoacán desde tiempos prehispánicos hasta la independencia, mismo que concluyó el 10 de febrero de 1942. El mural no fue 
encargado por Cárdenas, pero sí era de su agrado, pues era un reflejo fiel de los ideales de la época y no solo tenía fines decorativos sino didácticos, por la historia pictórica que narraba.

Las obras materiales hasta aquí referidas tendieron a mejorar la calidad de vida de los patzcuarenses y coadyuvar de manera indirecta a la colocación de Pátzcuaro en el panorama estatal y nacional. Pero para recibir a más visitantes era necesario dar a los empresarios las facilidades necesarias para abrir más y mejores servicios de alimentación y hospedaje. A principios de 1938, de acuerdo a un programa de inversiones que contribuyese al fomento del turismo, que diera comodidad a los viajantes y permitiera conservar el ambiente y las tradiciones regionales, la Azteca Compañía Mexicana de Seguros S. A. comenzó la construcción del hotel Posada Don Vasco, que abrió sus puertas al público en enero de 1939. En 1942 se inauguró el hotel Posada de la Basílica, al que seguiría el hotel Imperial, la Posada de la Rosa, la posada de las señoritas Carranco, entre otros lugares de hospedaje, que fueron sustituyendo a los antiguos mesones y sumándose a los hoteles existentes, como el De la Concordia, el Ocampo y el Del Lago.

En el caso de la Posada Don Vasco, ésta fue edificada en el nuevo camino que comunicaba el centro de Pátzcuaro con la estación del tren, conocida después como avenida de Las Américas, ahora Lázaro Cárdenas. Su estilo neocolonial estaba acorde con el tipo de construcciones de la época y había sido diseñado para el visitante que buscaba en Pátzcuaro las comodidades de la arquitectura moderna, pero el aspecto de la arquitectura típica michoacana. Su promoción a nivel nacional e internacional, a través de anuncios de periódico, guías turísticas y postales, fue amplia, lo que permitió que en poco tiempo se posicionara como uno de los hoteles favoritos por los turistas. El resto de los hoteles antes mencionados, a excepción del hotel $\mathrm{Del}$ Lago, tuvieron a su favor que estaban ubicados en el centro de la ciudad, en auténticas casonas coloniales, adaptados, de igual manera, a las exigencias de ese momento. Además, la mayoría de lugares para hospedaje ofrecían alimentos típicos del lugar, entre los que destacaba el pescado blanco, único en el mundo.

\section{Ilustración 1: Taquilla del teatro Emperador Caltzontzin.}

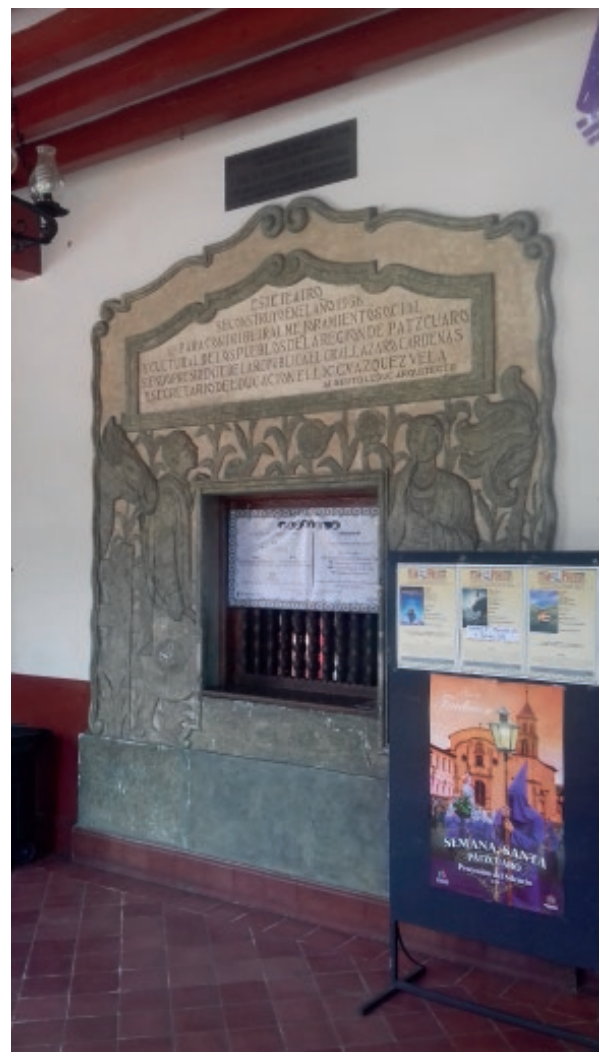

Fuente: Fotografía del autor, abril de 2018. 


\section{Legislación y organización social en pro de la conservación del aspecto típico.}

Para garantizar la conservación de poblados "típicos" y con bellezas naturales, como era el municipio de Pátzcuaro, el gobierno federal consideró necesario crear una legislación al respecto. En quince años, a partir de 1929, el Estado emitió al menos cuatro documentos legales que apoyaron el fomento turístico de los mismos mediante diversas acciones. El primer decreto que se publicó en 1929 abordaba dos puntos clave: el turismo regional y el mejoramiento de los poblados con este potencial. Para el año siguiente se publicó la Ley de Protección de Inmuebles Históricos o Artísticos. Derivado de esta ley se estableció que las casas conservaran su aspecto arquitectónico y se invitó a pintarlas de blanco y rojo, se conformó la Comisión de Conservación y se aclaró que el Ayuntamiento determinaría la zona dentro de la cual no podrán construirse nuevos edificios sin sujetarse a las disposiciones del Departamento de Control de Inmuebles Históricos o Artísticos que adquiría la obligación de vigilar por que se conserven las características regionales de la arquitectura (García, 2003: 55). En 1931 se decretó en México la Ley de Protección y Conservación de Monumentos y Bellezas Naturales, incluyendo la conservación del "aspecto típico y pintoresco" de los poblados. Luego, en 1943, se publicó la Ley Reglamentaria para la Conservación del Aspecto Típico y Colonial de la ciudad de Pátzcuaro. Esta ley se enfocaría a la necesidad de conservar de manera específica la imagen de la ciudad para que pudiera ser apreciada tanto por los residentes locales como por los visitantes. Sin embargo, era necesario contar con el equipamiento y la infraestructura necesaria, destacando la apertura de más y mejores hoteles (García y Martínez, 2012: 86-87).

En Michoacán, varias localidades recibieron apoyo para desarrollar el turismo; sin embargo, el sitio que mejor reunía las características para atraer al visitante era Pátzcuaro.

Un sitio que como pocos conjugaba múltiples factores, desde la carga simbólica de los tres grandes bloques históricos de México - prehispánico, virreinal e independiente-, manifestaciones culturales y tradiciones fuertemente arraigadas, una imagen de arquitectura típica y un paisaje natural imponente enmarcado por el lago de Pátzcuaro, símbolo de unión de los pueblos de la zona lacustre desde la época prehispánica (García y Ettinger, 2012: 5).

No obstante la importancia de fijar un cuerpo legal, probablemente éste no habría sido tan efectivo en el tema de la conservación de la imagen urbano-arquitectónica de Pátzcuaro sin una organización social que vigilaba su cumplimiento y, de alguna manera, concientizara al resto del pueblo sobre la necesidad de mantener esa imagen para el turista y para ellos mismos. En la década de 1930 la Sociedad de Historia de Pátzcuaro, conformada por Luis Ortiz Lazcano, Manuel Arriaga, Rosendo Ortega, Domingo Toro y otros personajes, estaba encargada de proteger la memoria histórica de la ciudad, al igual que los edificios y objetos que representaran el pasado de Pátzcuaro. En varias ocasiones este grupo y el resto de los ciudadanos evitaron atentados por parte de particulares, e incluso de presidentes municipales, en contra del patrimonio común. En 1935 Salvador Solchaga, un vecino de Pátzcuaro que trabajaba en la Secretaría de Educación Pública, informó a la Dirección de Monumentos Coloniales de México que el Ayuntamiento de Pátzcuaro pensaba demoler lo que quedaba del templo de la Tercera orden y la fuente de San Miguel. Ante esta situación, la Sociedad de Historia de Pátzcuaro, solicitó al presidente de la república Lázaro Cárdenas que interviniera para que se suspendieran las obras. Al ver la inconformidad de la sociedad local, el mandatario envió un oficio al presidente municipal de Pátzcuaro José Ramos Chávez indicándole que no demoliera la capilla y la pila (CDAGJE, 1935, 30.55/50). Algo similar sucedió en 1944, cuando se supo que el presidente Maurilio Flores y el diputado Ochoa Rentería pensaban dividir la plaza mayor para crear una pista de patinaje. Por fortuna, la intervención del licenciado Antonio Arriaga, director del museo michoacano, de Manuel Toussaint, director del Instituto de Investigaciones Estéticas de la UNAM, de los miembros de la recién formada Junta para la protección de la ciudad de Pátzcuaro: Luis Ortiz Lazcano y Antonio Salas León, así como de Jorge Enciso, coordinador nacional de la Dirección de Monumentos Coloniales, y de la prensa, evitó que el proyecto se efectuara (CDAGJE, 1944: 3).

En 1936 se formó un grupo vecinal denominado Sociedad Amigos de Pátzcuaro, cuya finalidad era fomentar el turismo y conservar el aspecto típico de la ciudad (AHMP, actas de cabildo, 1936: 54). Poco después se formó el Comité Pro Turismo, que tenía como objeto dar protección del turista, brindándole todas las comodidades necesarias y evitar que fuera víctima de abusos de cualquier tipo, pues se tenía la premisa de que la conservación de la ciudad con fines turísticos era estéril si no se trataba al visitante con amabilidad y honestidad. En efecto, los abusos sucedían, como lo denunciaba un periódico, cuyo 
encabezado decía: "Explotación inicua a los turistas. En el Hotel del Lago, de la estación de Pátzcuaro, se hace una pérfida labor en contra del turismo, por el exorbitante abuso que con los visitantes se comete". La denuncia provenía de un turista anónimo que aseguraba que los empleados de dicho hotel no quisieron venderle alimentos con el argumento de que este servicio era únicamente para los huéspedes y que los precios por habitación eran muy elevados (Heraldo Michoacano, noviembre 19, 1938: 2, 15).

\section{El arte y la identidad nacional}

En las décadas de 1920 y 1930, el sentimiento nacionalista, como reacción a la agitación política y social que representó la Revolución Mexicana, tuvo su reflejo en la arquitectura y demás obras artísticas, como la escultura y la pintura mural. En el caso de Pátzcuaro, que tenía una arquitectura bien definida y característica de la región lacustre, también se integraron al medio urbano nuevas manifestaciones arquitectónicas y artísticas sin que se tenga noticia de haber rechazo por parte de la ciudadanía.

La primera obra de envergadura en el municipio la promovió Lázaro Cárdenas desde 1931, cuando mandó levantar en la cumbre de la isla de Janitzio un edificio de 42 metros de altura, desde su base, que serviría de museo, mirador y monumento, pues su forma exterior era la del prócer héroe de la patria José María Morelos y Pavón. Fue construido por el escultor Guillermo Ruiz, en colaboración con Juan Cruz Reyes y Juan Tirado Valle, utilizando concreto armado y cantería como revestimiento. Después de su conclusión en 1934, Ramón Alva de la Canal pintó en su interior 56 paneles con escenas de la vida de Morelos y episodios de la Independencia de México (Fernández, 1936: 54). Además de rendir homenaje al héroe nacional, el monumento tenía una finalidad didáctica, dirigido sobre todo a los turistas, quienes además podían subir a través de una angosta escalera hasta el puño de la figura de Morelos, desde donde se podía tener una amplia visión panorámica del lago.

El 22 de agosto de 1936, con anuencia del presidente Cárdenas, se inició en la colonia Revolución, cerca de la estación del ferrocarril de Pátzcuaro un monumento significativo, aunque poco conocido, dedicado a la clase obrera y a la Revolución Mexicana, mismo que se inauguró el 20 de noviembre de ese año, conmemorando los dieciséis años del inicio de la Revolución Mexicana. Al frente del monumento se encuentran talladas las figuras de un militar, dos civiles y una mujer sosteniendo una bandera con la leyenda: "Obrero, la Revolución espera de ti lealtad a tus hermanos de clase".

Dos años después, el presidente Lázaro Cárdenas encargó al maestro escultor Guillermo Ruiz dos importantes monumentos de bronce de tres metros de altura para ser erigidos en Pátzcuaro. El primero se levantó a la memoria de la heroína doña Gertrudis Bocanegra en la plazuela que llevaba su nombre desde $1932 .{ }^{2}$ La figura se alza sobre un pedestal de base cuadrada, terminado en cantera y decorado con una placa de bronce en alto relieve que representa el suplicio de la señora Bocanegra. El otro monumento fue dedicado al emperador tarasco Tangaxoan II y se colocó en una glorieta, a la salida a Morelia. Fue montado sobre un pedestal art decó, de base cuadrada, terminado en cantería, de 3.64 metros de alto y decorado con cuatro placas de cobre en alto relieve, que ilustra la genealogía del último rey tarasco y relata escenas de su vida y tormento.

Por otro lado, para que los turistas y vecinos locales pudieran disfrutar de la vista panorámica del lago de Pátzcuaro y pueblos circundantes, el presidente Cárdenas y el gobernador del estado Rafael Ordorica, apoyaron el empedrado de un camino que llevaba a la cumbre del cerro del estribo, al poniente de la ciudad, donde se construyó un mirador con el nombre de Tariácuri, en honor a un antiguo gobernante tarasco. Era la continuación del famoso Mirador de los Balcones que se ubicaba en las faldas del mismo cerro y que había sido popular en las décadas anteriores, como lugar de paseo. En el nuevo mirador se colocó un kiosco de concreto diseñado por don Luis Ortiz Lazcano, cuyos pilares simulaban ramas de árbol.

De junio a julio de 1938 se construyó otro mirador, ahora en cerro colorado, conocido como Estribo Chico. Fue diseñado y construido por el arquitecto Antonio Llamosa y por el ingeniero Roberto Mejía Ortiz, comisionados por el gobierno del estado para embellecer la ciudad (Surco, julio 10, 1938: 1, 4). En dos muros del edificio principal de este lugar, el pintor Roberto Cueva del Río realizó pinturas con escenas de indígenas que representan los temas de El tianguis o El mercado y La danza del pescado (Record, junio 22, 1951: 1, 7). Cueva también fue contratado para pintar frescos en una escuela primaria de la isla de Yunuén y en 1937 decoró el auditorio del Teatro Emperador Caltzontzin con el tema El lago de Pátzcuaro; además, en el vestíbulo del segundo piso, elaboró un fresco que representa El encuentro del Rey Tanganxoan II y el conquistador Cristobal de Olid. Por último, en 1943 decoró el comedor de la quinta Eréndira -hoy ocupado por la sala de banderas del CREFAL- con un gran mural llamado Historia 
y Paisaje de Michoacán. En la biblioteca de este mismo edificio Fermín Revueltas pintó entre 1930 y 1931 un mural con escenas de la Conquista, que sirvió de inspiración para uno de los altos relieves que utilizó Guillermo Ruiz para decorar el pedestal de la escultura dedicada a Tangaxoan.

\section{Ilustración 2: Pintura mural de La danza del pescado, de Cueva del Rio.}

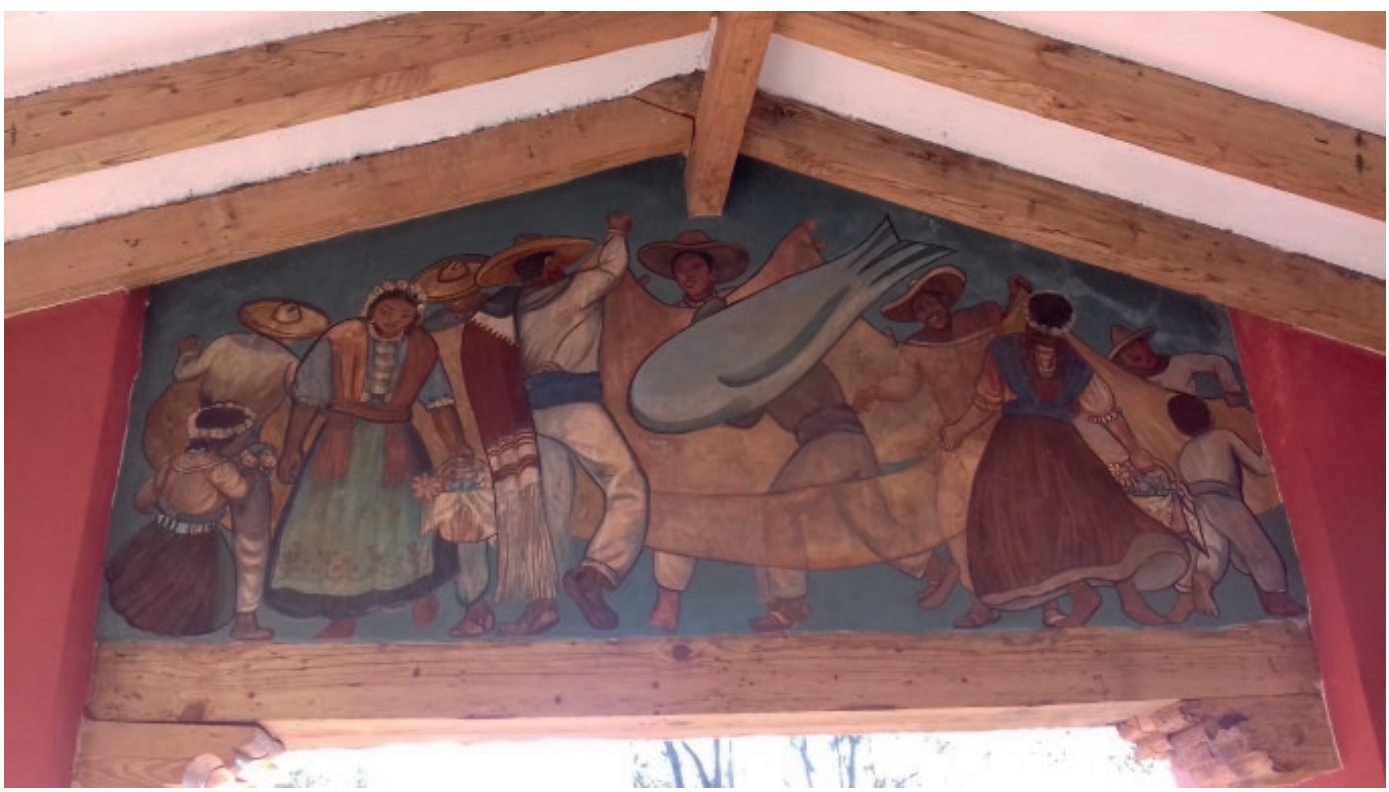

Fuente: Fotografía del autor, noviembre 2018.

Al terminar la década de 1920, el gobierno federal expropió los terrenos colindantes a la estación del tren, en lo que había sido la hacienda Ibarra, para formar la colonia que llevaría el mismo nombre. Luego, entre noviembre de 1930 y el resto del siguiente año, el entonces gobernador del estado Lázaro Cárdenas dotó de amplios solares a un grupo de exmilitares cercanos a él, en un terreno de su propiedad al noreste con la colonia Ibarra y al sur del lago, formando la colonia Morelos. Una vez que el predio fue donado se trazó de forma radial y en catorce amplios solares se construyeron al menos el mismo número de quintas, de estilo neocolonial y neo-indigenista, algunas con reminiscencia art decó. Entre otras, se levantaron las quintas San Ángel, El Fresno, Calimaya, Rosa Elena, Atzimba, Los Tres Reyes, de Efraín Buenrostro, la quinta del general Martín del Campo y la del general Carlos Moya. Cerca de ahí, en lo que entonces era una isla, el general Francisco J. Múgica, ex gobernador de Michoacán y amigo cercano de Cárdenas, mandó construir una quinta neocolonial conocida como Tzipecua (Martínez, 2016: 141-142).

La casa de descanso de Lázaro Cárdenas, conocida como Quinta Eréndira, fue otra de las construcciones que se levantaron en Pátzcuaro durante este periodo. Estaba en lo alto de una loma pedregosa, a unos metros de la estación del ferrocarril, y desde su mirador se podía ver de frente la isla de Janitzio y la estatua de Morelos que él mandó construir. La quinta fue proyectada e iniciada en 1927 por el arquitecto Alberto Le Duc con un diseño moderno, pero más tarde fue remodelada en un estilo neocolonial y neo indigenista, terminándose hasta 1940 (García, 2017: 148-149).

Caso aparte fueron las primeras gasolineras abiertas en Pátzcuaro después de 1930, como las que se ubicaban en la salida a Morelia y en la calle Federico Tena, respectivamente, que pertenecían a particulares pero habían sido diseñadas con un estilo neocolonial y decoradas con pintura mural, reflejando la moda de la época pero también evidenciaban claras intenciones de ofrecer al turista lo que buscaba, pues a decir del gobernador del estado Gildardo Magaña "el visitante extranjero no quiere ver habitaciones y edificios idénticos a los que está acostumbrado a ver; el turista es un individuo exótico que busca siempre cosas nuevas" (Surco, febrero 2, 1938). 


\section{Ilustración 3: Quinta Eréndira del general Lázaro Cárdenas.}

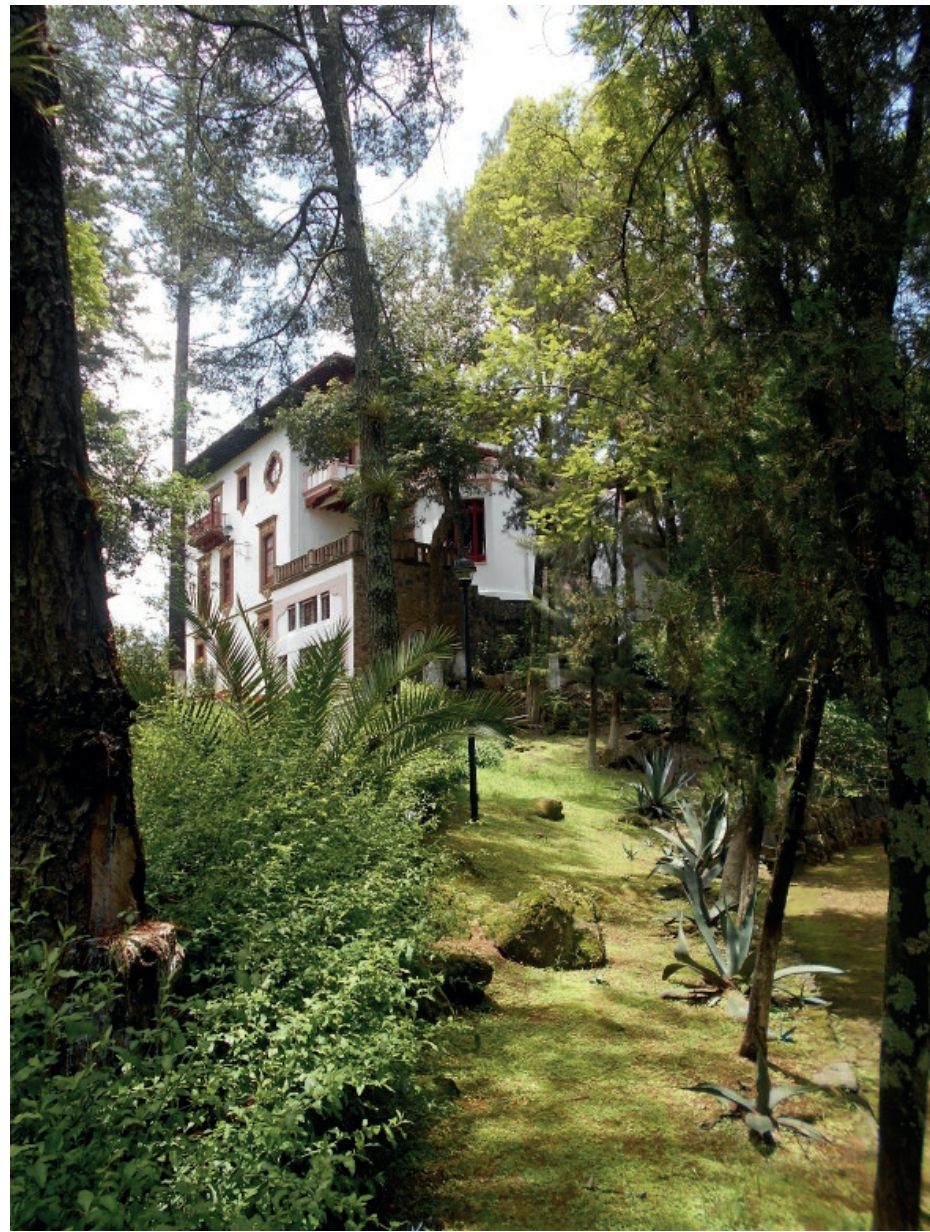

Fuente: Fotografía del autor, noviembre 2017.

\section{Pátzcuaro visto desde afuera}

Pátzcuaro fue uno de los municipios que más se beneficiaron del gobierno de Lázaro Cárdenas del Rio, quien lo conocía bien y sabía de su potencial que tenía como punto de interés para los visitantes nacionales y extranjeros. Es por eso que una vez que obtuvo la gubernatura del estado de Michoacán, pero sobre todo siendo presidente de la República Mexicana, implementó medidas para conservar el aspecto colonial de la ciudad del lago y atraer al turismo, ya que consideraba esta fuente de ingresos de gran porvenir para el desarrollo industrial, agrícola y comercial de la ciudad y la región (García, 2015: 487).

El imaginario que se creó de Pátzcuaro y los pueblos ribereños hacia el extranjero se debió en gran parte a las fotografías que los mismos visitantes tomaron, muchas de las cuales se publicaron en revistas, guías turísticas o postales, enalteciendo la idea romántica y nacionalista del indígena y su forma de vida provinciana. Los fotógrafos locales y visitantes aprovecharon la belleza de Pátzcuaro, el lago y las islas, principalmente la de Janitzio, capturaron edificios religiosos, fuentes públicas, portales y calles "pintorescas", pescadores, vendedoras de pescado, aguadores e indígenas en sus quehaceres cotidianos (The Milwaukee Sentinel, agosto 15, 1943: 49). Eran extractos de la realidad, elegidas intencionalmente para mostrar escenas que identificaban el lugar, incluso, algunas eran creadas artificialmente para 
realzar el carácter provinciano, tradicional de la ciudad y los pueblos del lago. En cualquiera de los dos casos, como sucede siempre, había una intención: el fotógrafo o pintor decidía qué es lo que quería mostrar a los demás.

Las fotografías y la imagen que se proyectó de Pátzcuaro, del lago y de los pueblos ribereños reflejaban parte de los ideales de la posrevolución, donde el indígena resurgía como una figura protagonista de la sociedad, heredera de sangre de los pobladores originarios, que daban identidad al estado de Michoacán. Cuando el objetivo del fotógrafo era la arquitectura, solían tomarse los templos, casas, plazas, fuentes y demás elementos representativos de la arquitectura michoacana y patzcuarense. Otras de las tomas, por ejemplo de las gasolineras o del hotel Posada Don Vasco, que eran publicadas en las guías turísticas y se difundían como postales, tenían la intención de ofertar servicios que permitirían al visitante acceder a las mejores comodidades y servicios que la vida moderna exigía, pero sin perder el gusto por la arquitectura tradicional mexicana (Jolly, 2018: 139-140).

Del periodo postrevolucionario -1920-1950- se conocen fotografías tomadas por Hugo Brehme, Pierre Verger, Tina Modotti, Anton Bruehl, Rafael Saucedo, Gabriel Zavala Garibay, Guillermo Valdés M., Gonzalo Melgoza González, Luis Márquez, Enrique A. Cervantes, los que firmaron como Díaz, Navarro, Alanís, Mejía, R. Raya, Chávez Ruíz, Floresll y Desentis Jr.; además de los que trabajaban para agencias como México fotográfico, FEMA, CEPSA Y POSTAMEX; los que publicaron en periódicos, revistas (Saavedra, 1925 o La Esfera, 1929), guías turísticas, ${ }^{3}$ libros nacionales (Toussaint, 1942) y extranjeros, sin contar las fotos de películas, como Jack Draper para el filme Janitzio (1935), Gabriel Figueroa, para la película Maclovia (1948), o los documentales Morelia, Pátzcuaro y Uruapan (1945) de J. Sierra, Pátzcuaro (1949) de Luis Osorno Barona, Así es Michoacán (1959) de Max Liszt, entre otros.

En la música, Pátzcuaro, su lago y algunos personajes de la historia de la ciudad fueron inmortalizados en este periodo por distintas personas. Alfonso Esparza Oteo compuso el vals Luna de Pátzcuaro, Agustín Lara dedicó un tema a Janitzio, Silvestre Revueltas compuso el tema sinfónico Después de Janitzio, y Miguel Bernal Jiménez, compuso el drama sinfónico Navidad en Pátzcuaro y Tingambato, así como uno dedicado a Tata Vasco, que fue estrenado en Pátzcuaro el 15 de febrero de 1941. Además, varios poetas dedicaron sus versos a los paisajes patzcuarenses, figurando Manuel Gutiérrez Nájera, con su composición de El lago de Pátzcuaro, mientras que varios pintores retrataron escenas de la vida cotidiana o paisajes, entre los que destaca Diego Rivera con el lienzo La Ofrenda en Janitzio, de 1947.

Un evento que favoreció el turismo en la ciudad fue la erupción del volcán Paricutín, en la sierra purépecha de Michoacán, el 20 de febrero de 1943, ya que numerosos investigadores, exploradores, fotógrafos y pintores hicieron escala en Pátzcuaro, antes de pasar a admirar, estudiar y fotografiar el joven volcán. Muchas de las fotografías que se conocen de la ciudad y el lago son de estos años, aunque pocas están fechadas y no todas tienen el nombre de quien las tomó.

Hasta aquí debe quedar claro que no todas las obras materiales e inmateriales realizadas en Pátzcuaro desde la década de 1920 hasta mediados del siglo XX fueron ordenadas o financiadas por el gobierno federal que encabezaba Lázaro Cárdenas, pues muchas de ellas fueron gestionadas y realizadas por el municipio, los ciudadanos y las juntas de conservación. Sin embargo, es claro que el líder nacional estuvo interesado en el progreso de la ciudad, por lo que en muchas ocasiones se ocupó personalmente de que aplicaran los recursos necesarios para llevar a cabo los proyectos que había solicitado. Incluso, después de que había dejado la presidencia de la República y hasta antes de su muerte siguió trabajando en proyectos relacionados a la educación de los indígenas de la región lacustre y la reforestación de los bosques de la zona. La figura paternal que había generado durante sus años de mandatario del estado y del país, provocaba que la gente de Pátzcuaro lo buscara para pedirle apoyo en distintos proyectos. En 1942, por ejemplo, el señor Jorge Braniff y su esposa María Concepción Lascurain Landa pidieron a don Lázaro Cárdenas un lugar para instaurar una casa hogar. El lugar que les fue ofrecido era el ex convento de San Francisco, que después de tener las reparaciones y adaptaciones necesarias funcionó como la Hogar Providencia de Don Vasco, a partir de 1943 (Martínez, 2016: 50-52).

\section{Conclusiones}

Lázaro Cárdenas es más conocido por la reforma agraria, la nacionalización de la industria petrolera y por haber brindado asilo político a exiliados españoles durante la guerra civil española, pero, su proyecto de Estado buscaba en un sentido amplio desarrollar la economía, los servicios de salud, la educación, las relaciones exteriores, las comunicaciones y las obras públicas del país. En Michoacán, 
su estado natal, y principalmente en Pátzcuaro, puso gran empeño para que lograra integrarse a su proyecto mediante distintas vertientes, entre estas, el desarrollo turístico.

El presente estudio deja ver que, como parte de sus políticas de gobierno, Cárdenas impulsó el turismo en el país, pero puso especial empeño en la ciudad de Pátzcuaro, para que esta pudiera aprovechar sus atractivos naturales y arquitectónicos, lo que también permitió la conservación de los mismos. Como parte importante del impulso que dio a Pátzcuaro, se aseguró de ofrecer todos los recursos que fueran necesarios para que la ciudad contara con servicios e infraestructura turística, pero también para que fuera embellecida con obras de arte, como monumentos y pintura mural, que reflejaban el orgullo de su herencia histórica y reforzaban su identidad.

Los objetivos del presidente no solo estaban limitados a la actividad turística, sino que estaban fijados para que los habitantes de la ciudad y los pueblos circunvecinos mejoraran sus condiciones de vida en todos los aspectos y por todos los medios. En el municipio, Cárdenas también mandó construir escuelas, estableció vedas para proteger la tala excesiva de los bosques, creó sindicatos de obreros y campesinos y repartió tierras agrícolas, entre otras acciones.

Por el "interés en el progreso y adelanto de la ciudad", que tuvo el mandatario, en 1931, antes de que efectuara la mayor parte de su obra, el Ayuntamiento de Pátzcuaro declaró a Lázaro Cárdenas del Río hijo predilecto de la ciudad, y cuatro años después se ratificó el nombramiento (AHMP, actas de cabildo, 1933: 42, 43 b). En Pátzcuaro, como en muchos poblados de Michoacán y del país, se tiene a "Tata Lázaro" en un lugar privilegiado de la memoria colectiva. El monumento en su honor levantado a un costado de su quinta Eréndira después de su muerte es un recuerdo tangible del legado que dejó el mandatario michoacano en la ciudad del lago.

\section{Bibliografía}

Barriga, Eduardo y Fernando Mendoza 2010. Pátzcuaro en breve. Pátzcuaro: Gobierno del Estado de Michoacán.

Cervantes, Enrique A. 1932. Pátzcuaro: s. e. (álbum de fotografías en blanco y negro).

Fernández, Justino 1936. Pátzcuaro. Su situación. historia y características. México. Talleres de impresión de estampillas y valores. Secretaría de Hacienda y Crédito Público.

García Sánchez, Eder y Catherine R. Ettinger McEnulty 2012. "Los imaginarios de arquitectura típica y el turismo en el México posrevolucionario". V Foro Internacional de Investigación en arquitectura y IX Foro de Avances de Investigación en Arquitectura. Facultad de Arquitectura. Universidad Michoacana de San Nicolás de Hidalgo. Morelia.

García Sánchez, Eder y José Manuel Martínez A. 2012. "Espacio, forma y función. Conservación y cambios en el centro histórico de Pátzcuaro". En Estudios sobre vivienda y espacio urbano en los centros históricos. Morelia. Universidad Michoacana de San Nicolás de Hidalgo. Secretaría de Educación Pública - PROMEP. Morevallado.

García Sánchez, Eder 2015 a. "Entre el imaginario y lo imaginado. Pátzcuaro y el turismo a principios del siglo XX". En Catherine R. Ettinger (coord.). Imaginarios de tradición y modernidad. México. MAPorrúa.

García Sánchez, Eder 2015 b. "El turismo en Pátzcuaro (México). Percepciones del visitante extranjero entre 1880-1920". Pasos. Revista de Turismo y Patrimonio Cultural, 13 (3), pp. 477-489.

García Sánchez, Eder 2003. "Pátzcuaro pintoresco. Entre imaginarios y turismo (1920-1950)". Tesis Maestría en Arquitectura. Investigación y Restauración de Sitios y Monumentos. Facultad de Arquitectura. Universidad Michoacana de San Nicolás de Hidalgo.

García Sánchez, Eder 2017. "La arquitectura nacionalista del cardenismo. Las quintas campestres y el proyecto cultural en Michoacán (1927-1950)". Tesis de Doctorado en Arquitectura. Facultad de Arquitectura. Universidad Michoacana de San Nicolás de Hidalgo. 2017.

Jolly, Jennifer 2018. Creating Mexico. Art. tourism and Nation building under Lazaro Cardenas. Austin. University of Texas Press. 2017. "Muralismo. Estado y Turismo en Pátzcuaro. Michoacán”. Crónicas. Número especial. México. Universidad Nacional Autónoma de México, pp. 83-93.

Krauze, Enrique 2003. General misionero. Lázaro Cárdenas. México. Fondo de Cultura Económica.

Macías, Pablo G. 1978. Pátzcuaro. Morelia. Gobierno del Estado de Michoacán.

Martínez A. José Manuel. 2016. Pátzcuaro, historias en el olvido. Morelia. Genotipo Gráficos.

Martínez A. José Manuel. 2017. "Una mirada al surgimiento del turismo en Pátzcuaro durante el porfiriato". Pasos. Revista de turismo y Patrimonio Cultural, 15 (2), pp. 409-418. 
Mercado López, Eugenio. 2015. "El turismo y la protección legal del aspecto típico de las poblaciones en el México posrevolucionario". Palapa, III (1), pp. 57-72.

Mercado López, Eugenio. 2018. "El turismo y su impacto en las políticas económicas, culturales y turísticas de México en las primeras del siglo XX: la perspectiva de la prensa de la época". Pasos, revista de turismo y patrimonio cultural, 16 (3), pp. 671-683.

Mercado López, Eugenio. 2016. "Patrimonio cultural y turismo en el México posrevolucionario". Pasos, revista de turismo y patrimonio cultural, 4 (4), pp. 1027-1040.

Saavedra, P. 1925. "En tierra de Tarascos". Magazine de Geografía Nacional, 1 (2), México.

Toussaint. Manuel 1942. Pátzcuaro. México. Universidad Nacional Autónoma de México.

\section{Notas}

1 Gracias a un grupo de accionistas formado por Luis Ortiz Lazcano, Ramón Carranco, Santiago Ramos, Fructuoso Obregón, Jesús Monroy, Luis G. Mota, Nicolás Ugalde, Carlos Báez, Aurelio Ruíz Oseguera, Ildefonso Sánchez, Luis M. Alfaro, Jesús Mendoza, Julio Leal y Juan Mejía. AHMP, Libro de cabildo, 18 b, 22.

2 En este teatro el mismo Cárdenas había llevado a cabo, en enero de 1929, el Congreso Estatal del Frente Único de Trabajadores del Estado de Michoacán, y fundó la Confederación Revolucionaria Michoacana del Trabajo, CRMDT.

3 Como Rafael García, fotógrafo de la revista Mapa o Nelson Morris de Modern Mexico. Mapa, noviembre 8, 1934. Modern Mexico, marzo 10, 1947. 